\title{
Editorial
}

\section{Effects of OBRA regulations in the USA}

As part of the Omnibus Budget Reconciliation Act of 1987 (OBRA '87), federal legislation was passed by the US Congress designed to make nursing homes more responsive to the needs of elderly patients. Individual treatment planning and many aspects of care were addressed with the intention of increasing the emphasis on rehabilitation in nursing homes in order to bring each resident to the highest practical levels of functioning and independence. ${ }^{1}$ The Health Care Financing Administration (HCFA) subsequently proposed guidelines for surveyors to implement these regulations through surveys of Medicare and Medicaid certified nursing facilities (NFs). These guidelines were not implemented until 1 October 1990. We have now had about 18 months' experience in the USA with these regulations by which to judge their effectiveness and to assess changes in physicians' behaviour as a result of these requirements.

OBRA '87 laid down specific requirements concerning the frequency and interval of physician visits, the requirement that each NF have a physician medical director, and regulations concerning the prescribing and monitoring of restraints and psychotropic drugs. These requirements represented a major change in North American medicine as, for the first time, there was a need to document specific indications for a treatment in order to justify prescription. Garrard et al. reviewed the charts of over three thousand nursing home residents between 1976 and 1985.2 They retrospectively followed each resident for two years to determine whether 'ineligible neuroleptic use' had occurred, as defined by OBRA '87. Almost one-third of patients had received a neuroleptic at some time during the study period. Residents receiving neuroleptics were more likely to be restrained physically. Approximately half of neuroleptic use failed to meet subsequently implemented HCFA guidelines.

Mental illness is common in nursing homes. ${ }^{3-5}$ Most nursing home psychiatric care is performed by primary care physicians 6 and many studies demonstrate overuse of neuroleptics and other psychotropic drugs, ${ }^{2,7-9}$ even though they are of only marginal use for agitation with organic mental syndromes. ${ }^{10}$ The use of physical restraint in American nursing homes is common, ${ }^{11}$ and the use both of restraints and psychotropic drugs influences the incidence of falls with injury in NF residents. Many other complications of neuroleptics and restraints have also been described. ${ }^{12,13}$

These identified problems in NFs provided the grass-roots motivation for OBRA '87. However, because the regulations originated outside the 


\section{Editorial}

medical profession, they may stem from a prejudiced viewpoint or be overly simplistic or dogmatic. In addition, the subject material is so complex that it may have proved difficult to formulate and enforce well intentioned regulations.

The American Medical Directors Association (AMDA) has studied some of the consequences of OBRA '87 (PR Katz, personal communication). The 699 physicians surveyed considered 'staying abreast with regulations' as the most challenging of all their duties, and considered 'dealing with regulators' as the area in which they most needed assistance from AMDA. Of the study sample, $73 \%$ reported an increase in the time required to perform their administrative duties - an average increase of $30 \%$. The AMDA study indicates that $10 \%$ of medical directors expect to leave this area of work within two years, and estimate that $10 \%$ of their attending physicians have already done so. Low reimbursement, regulations and paperwork repeatedly emerge as reasons for these drop-outs.

Against this, there are early indications of improvements in quality of care since OBRA '87 was implemented. An American Association of Homes for the Aging survey reports a $47 \%$ decrease in restraint use and a $28 \%$ reduction in drugs used for behaviour control between 1989 and 1991.14

Samuel Kidder of HCFA's Health Standards and Quality Bureau has shared anecdotal reports from facilities in eight states indicating substantial reductions in antipsychotic drug use over recent months (SW Kidder, personal communication). In Wisconsin, an $18 \%$ reduction in antipsychotic use was found between October 1989 and 1990 among $31000 \mathrm{NF}$ residents. Several of these sources offered the subjective opinion that residents whose antipsychotropic treatment had been reduced or discontinued showed no escalation of problematic behaviour and displayed better functional status, with improved communication, self-feeding and ambulatory abilities. No objective data were presented, however.

Though there are indications that OBRA '87 regulations have been effective, they are also perceived as burdensome. HCFA now reimburses even less for a nursing home visit in many states than it did prior to OBRA '87, with its increased demands on physician time. Government interventions to change practice standards have often created barriers or threatened punitive actions - negative tactics that may not be all that effective. As a result, some physicians may stop working in long-term care.

David A Smith, Professor, Family Medicinel Psychiatry, University of South Dakota School of Medicine, Dakota Human Services Center, Yankton Office, 1000 West 4th Street \# 3, Yankton, SD 57078-3718, USA.

\section{References}

1 Health Care Financing Administration. State operations manual. Maryland: US Department of Health and Human Services; 1989. Transmitted 232.

2 Garrard J, Makris L, Dunham T, et al. Evaluation of neuroleptic drug use by nursing home elderly under proposed Medicare and Medicaid regulations. JAMA 1991; 265: 463.

3 Zimmer JG, Watson N, Treat A. Behavioral problems among patients in skilled nursing home facilities. AJPH. 1984; 74: 1118 .

4 Chandler JD, Chandler JE. The prevalence of neuropsychiatric disorders in a nursing home population. J Geriatr Psychiatry Neurol 1988; $1: 71$.

5 Morriss RK, Rovner BW, Folstein M, German PS. Delusions in newly admitted residents of nursing homes. Am J Psychiatry 1990; 147: 299.

6 Smith DA. The family practitioner and psychiatric problems in the old. JAMA 1987; 257: 2288.

7 Beers M, Avorn J, Soumeral SD, et al. Psychoactive medication use in intermediate-care facility residents. JAMA 1988; 260: 3016.

8 Ray WA, Federspiel CF, Schaffner W. A study of antipsychotic drug use in nursing homes: epidemiologic evidence of misuse. Am J Public Health 1980; 70: 485.

9 Ray WA, Griffin MR, Schaffner W, et al. Psychotropic drug use and the risk of hip fracture. $N$ Engl J Med 1987; 316: 363.

10 Schneider LS, Pollock VE, Lyness SA. A meta-analysis of controlled trials of neuroleptic treatment in dementia. J Am Geriatric Soc 1990; 38: 553.

11 Tinetti M, Liu W, Marottoli R, Ginter S. Mechanical restraint use among residents of skilled nursing facilities; prevalence, patterns and predictors. JAMA 1991; 265: 468.

12 Meltzer HY ed. Psychopharmacology: the third generation of progress. Raven Press, New York, 1987.

13 Smith DA. Nursing home rights and physical restraints. J Med Direction; January 1992: 9.

14 Nursing homes report decreased restraint use. AGS Newsletter 1992; $21: 1$. 